\title{
Integrins: a role as cell signalling molecules
}

\author{
J L Jones, R A Walker
}

\begin{abstract}
Integrins form the major family of proteins that mediates cell-matrix interactions. As well as an adhesive function, it is increasingly apparent that integrins can transduce messages via classic signalling pathways and impact upon such fundamental cellular processes as proliferation, apoptosis, differentiation, and motility. Dysegulation of these processes are a feature of many malignancies. Altered integrin expression has been observed in many human tumours, and perturbation of integrin function or expression in experimental systems has demonstrated that altered integrin signalling may directly contribute to the development of the malignant phenotype.

(f Clin Pathol: Mol Pathol 1999;52:208-213)
\end{abstract}

Keywords: integrin signalling; proliferation; apoptosis; differentiation; invasion; matrix metalloproteinases; cancer

Cell-matrix interactions directly participate in the control of cellular differentiation, morphogenesis, proliferation, and migration, and thereby impact on such processes as embryogenesis, wound healing, inflammation, and cancer. Many of these interactions with the extracellular matrix are mediated by the integrin family of cell adhesion molecules. In addition to their adhesive function, integrins are now recognised as signalling molecules capable of transducing messages via classic signalling pathways, and integrin receptor function can be regarded as a key modulator of cellular behaviour. The aim of this review is to outline what is currently understood about the structural basis of integrin signalling, the role of integrins in modulating normal cell processes, and the potential contribution of altered integrin function in development of the malignant phenotype.

\section{Structural features of integrins}

The integrins form a family of heterodimeric cell surface receptors composed of noncovalently linked dissimilar $\alpha$ and $\beta$ subunits. ${ }^{1}$ To date , $15 \alpha$ and eight $\beta$ subunits have been described and these combine to form over 20 different receptors (table 1). ${ }^{1}$ Most integrins function as receptors for extracellular matrix (ECM) proteins; however, some family members, such as the $\beta 2$ integrins, and $\alpha 4 \beta 1$ integrin, mediate heterotypic cell-cell adhesion. The $a / \beta$ associations determine the ligand binding specificities of the receptor for various extracellular matrix proteins. Although some integrins, such as the fibronectin receptor $\alpha 5 \beta 1$, recognise only a single ligand, more commonly an integrin is capable of binding several ligands. ${ }^{2}$ There is further functional overlap in that several integrins may bind to the same matrix protein-for example, there are at least seven different receptors for fibronectin. In some cases the integrins bind to different regions of the ligand, as do the $\alpha 4 \beta 1$ and $\alpha 5 \beta 1$ receptors, ${ }^{3}$ whereas in other cases the integrins bind to the same region of the protein-for example, the binding of $\alpha 5 \beta 1$ and $\alpha 3 \beta 1$ to fibronectin. ${ }^{4}$ This apparant redundancy in the system suggests that integrins function as more than mere sticky molecules, and it is likely that interactions between specific receptors and distinct ligand binding sites can communicate unique information to cells.

Integrins are well adapted for the transmission of information from the extracellular environment into the cell. The cytoplasmic domains of both subunits of the integrin receptors interact with the cytoskeleton (fig 1). With the exception of the $\beta 4$ subunit, the $\beta$ chain cytoplasmic domains are relatively short, being composed of between 40 and 60 amino acids. They are highly conserved and they interact with the actin cytoskeleton via a range of cytoskeletal proteins such as $\alpha$-actinin, talin, vinculin, and tensin in the formation of focal adhesions. ${ }^{5}$ The $\beta 4$ subunit has a large cytoplasmic domain (>1000 amino acids long), which interacts with the intermediate filament cytoskeleton rather than the actin cytoskeleton. ${ }^{6}$ This integrin is a major component of hemidesmosomes-stable adhesive structures found in the basal cell layer of stratified and complex epithelia-and it has been shown recently that the cytoplasmic domain of $\beta 4$ integrin is essential for the formation of hemidesmosomes. ${ }^{7}$ From this diversity of receptor structure it is evident that a range of cellular responses could be initiated through binding of a single ligand.

\section{Integrin signalling mechanisms}

Integrins can mediate signalling by two mechanisms, so called "inside out" signalling and "outside in" signalling (fig 2). ${ }^{8} 9$ Inside out signalling is the mechanism by which a cell regulates the affinity state of its integrin receptors. ${ }^{8}$ It is thought to involve the propagation of conformational changes from the cytoplasmic domains of integrins to the extracellular binding site in response to intracellular signalling events. ${ }^{10}$ Several regions within the cytoplasmic domains of both $\alpha$ and $\beta$ subunits have been shown to be involved in regulating the affinity state of the integrin receptor. There is evidence that conformational changes within these regions, brought about through phosphorylation or dephosphorylation events, allow the 
Table 1 The integrin family and its ligands

\begin{tabular}{|c|c|c|c|}
\hline Receptor & & Ligand & Distribution \\
\hline \multicolumn{4}{|l|}{$\beta 1$ integrins } \\
\hline VLA-1 & $\alpha 1 \beta 1$ & Ln, Col & Broad \\
\hline VLA-2 & $\alpha 2 \beta 1$ & Ln, Col & Broad \\
\hline \multirow[t]{2}{*}{ VLA-3 } & $\alpha 3 \mathrm{~A} \beta 1$ & Ln, Col, Fn, Epiligrin & Broad \\
\hline & $\alpha 3 \mathrm{~B} \beta 1$ & Ln, Col, Fn, Epiligrin & Broad \\
\hline VLA-4 & $\alpha 4 \beta 1$ & Fn (V25), VCAM-1 & $\mathrm{B}$ and $\mathrm{T}$ cells, macrophages, neural crest cells \\
\hline VLA-5 & $\alpha 5 \beta 1$ & Fn (RGD) & Broad \\
\hline \multirow[t]{2}{*}{ VLA-6 } & $\alpha 6 \mathrm{~A} \beta 1$ & Ln & Broad \\
\hline & $\alpha 6 \mathrm{~B} \beta 1$ & $\mathrm{Ln}$ & Broad \\
\hline \multirow[t]{2}{*}{ VLA-7 } & $\alpha 7 \mathrm{~A} \beta 1$ & $?$ & ? \\
\hline & $\alpha 7 \mathrm{~B} \beta 1$ & Ln & ? \\
\hline \multirow[t]{2}{*}{ VLA-8 } & $\alpha 8 \beta 1$ & $?$ & ? \\
\hline & $\alpha v \beta 1$ & Fn, Vn & Epithelial cells \\
\hline \multicolumn{4}{|l|}{$\beta 2$ integrins } \\
\hline LFA-1 & $\alpha \mathrm{L} \beta 2$ & ICAM-1, ICAM-2, ICAM-3 & Leucocytes \\
\hline CR3, Mac-1 & $\alpha M \beta 2$ & C3bi, factor X, Fbn & \\
\hline p150, p95 & $\alpha \times \beta 2$ & C3bi, Fbn & \\
\hline \multicolumn{4}{|l|}{$\beta 3$ integrins } \\
\hline gpIIb/IIIa & $\alpha \operatorname{IIb} \beta 3$ & Fbn, Fn, vW factor, Vn, thrombospondin & Platelets \\
\hline VNR & $\alpha v \beta 3$ & Fbn, Fn, vW factor, Vn, thrombospondin & Endothelial cells, osteoclasts \\
\hline & $\alpha 6 \mathrm{~A} \beta 4$ & Laminin 5 & Epithelial cells \\
\hline & $\alpha 6 \mathrm{~B} \beta 4$ & Laminin 5 & Epithelial cells \\
\hline \multicolumn{4}{|l|}{$\beta 5$ integrins } \\
\hline \multirow[t]{2}{*}{$\beta 6$ integrins } & & & \\
\hline & $\alpha v \beta 6$ & Fn & ? \\
\hline \multirow{3}{*}{$\beta 7$ integrins } & $\alpha 4 \beta 7$ & Fn, VCAM-1, MadCAM-1 & Activated $\mathrm{B}$ and $\mathrm{T}$ cells, intraepithelial \\
\hline & & & lymphocytes \\
\hline & $\alpha \mathrm{E} \beta 7$ & E-cadherin & $\begin{array}{l}\text { Activated } \mathrm{B} \text { and } \mathrm{T} \text { cells, intraepithelial } \\
\text { lymphocytes }\end{array}$ \\
\hline \multicolumn{4}{|l|}{$\beta 8$ integrins } \\
\hline & $\alpha \mathrm{B} \beta 8$ & $?$ & $?$ \\
\hline & $\alpha 9 \beta 8$ & ? & ? \\
\hline
\end{tabular}

C3bi, inactivated complement component C3; Col, collagen; Fbn, fibrinogen; Fn, fibronectin; ICAM, intercellular cell adhesion molecule; LFA, leucocyte function antigen; Ln, laminin; MadCAM, mucosal addressin cell adhesion molecule; VCAM, vascular cell adhesion molecule; VLA, very late activation; VNR, vitronectiin receptor; $\mathrm{vW}$ factor, von Willebrand factor.

association of other proteins that can regulate the integrin activity state. ${ }^{11} 12$

Outside in signalling mediates signals from the extracellular matrix after integrin ligation and involves regulation of many fundamental cellular processes. ${ }^{8}$ It involves integrin-ligand binding and receptor clustering, with subsequent assembly of the focal adhesion

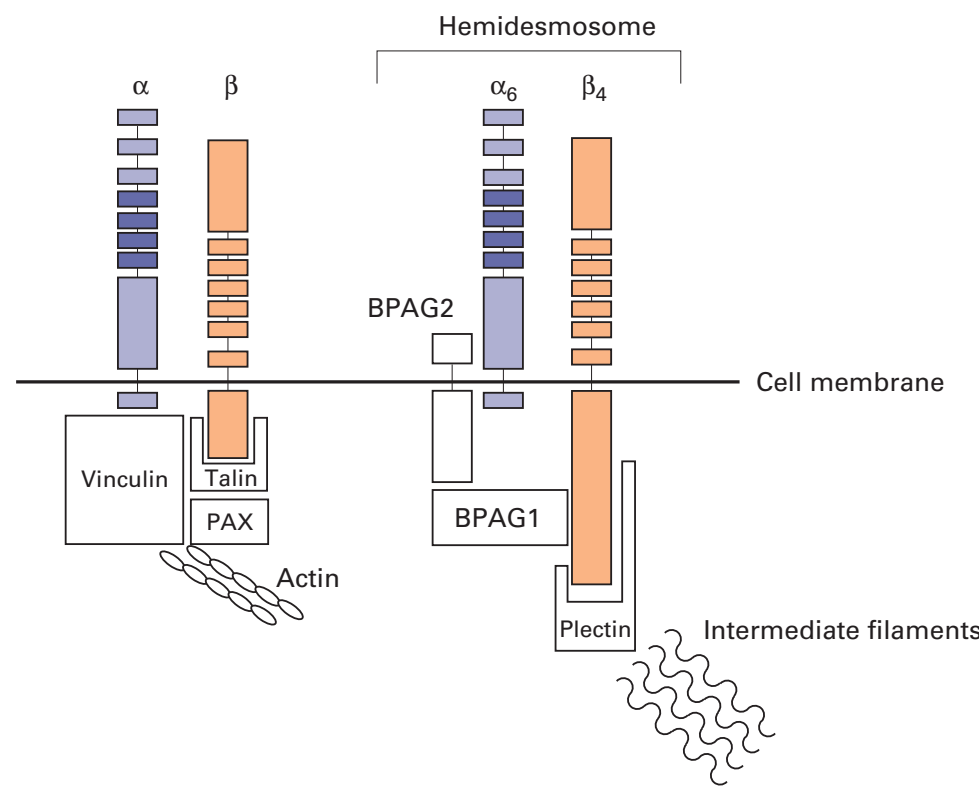

Figure 1 Cytoskeletal interactions of $\beta 1$ and $\beta 4$ integrins. The $\beta 1$ cytoplasmic tail interacts with the cytoskeletal proteins talin, vinculin, and paxillin (PAX), and via these proteins to the actin cytoskeleton. The a6 34 integrin is located in hemidesmosomes along with the transmembrane protein bullous pemphigoid antigen 2 (BPAG2). This complex is linked to the intermediate filament cytoskeleton via BPAG1 and plectin. plaque-a complex of cytoskeletal proteins and signalling molecules including paxillin, talin, vinculin, $\alpha$-actinin, tensin, and focal adhesion kinase (FAK). ${ }^{6}$ This process is dependent on the GTPase Rho A. ${ }^{13}{ }^{14}$ Phosphorylated FAK can also lead to activation of the mitogen activated protein (MAP) kinase pathway, probably via Ras activation, which can then influence gene expression. ${ }^{15} 16$

\section{Integrin control of cell function \\ PROLIFERATION}

One of the defining characteristics of normal cells is that they require anchorage to a substratum to proliferate. ${ }^{17}$ Although normal cells require mitogenic growth factors to proliferate, it is the coordinate response of a cell to both growth factors and integrin mediated signals that regulates the progression through the cell cycle (fig 3$).{ }^{18}$

A key event in the progression through the G1 phase of the cell cycle is hyperphosphorylation of the retinoblastoma protein $(\mathrm{Rb})$. In quiescent cells, hypophosphorylated $\mathrm{Rb}$ exists as a complex bound to the E2F family of transcription factors; phosphorylation of $\mathrm{Rb}$ leads to release of $\mathrm{E} 2 \mathrm{~F}$, which can then bind to $\mathrm{E} 2 \mathrm{~F}$ responsive elements, leading to transcription of several growth regulatory genes, including cyclin A. ${ }^{19-21}$ The phosphorylation status of $\mathrm{Rb}$ is regulated by cyclins, which in turn are regulated by mitogenic growth factors, either by induction of cyclin proteins or by repression of the cyclin dependent kinase (cdk) inhibitory proteins p21 and p27. ${ }^{20}$ It has been shown that mitogen induced progression through the 
G1 phase is dependent on cellular interaction with the extracellular matrix; both the induction of cyclin D1 mRNA and protein, and the reduction of cdk inhibitory proteins is minimal in the absence of cell attachment to a substratum. ${ }^{23}{ }^{24}$ This control of the cell cycle appears to be mediated via integrin induced reorganisation of the cytoskeleton. ${ }^{25} 26$

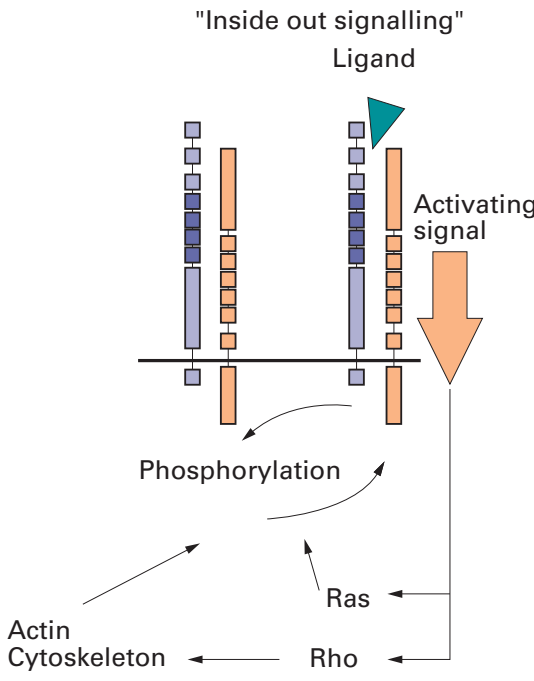

APOPTOSIS

As well as controlling progression through the cell cycle, integrin mediated cell anchorage plays a central role in the control of apoptosis. ${ }^{26}$ The term "anoikis" has been coined to describe the apoptosis that occurs when cells are detached from their matrix. Integrins that can activate tyrosine phosphorylation of the

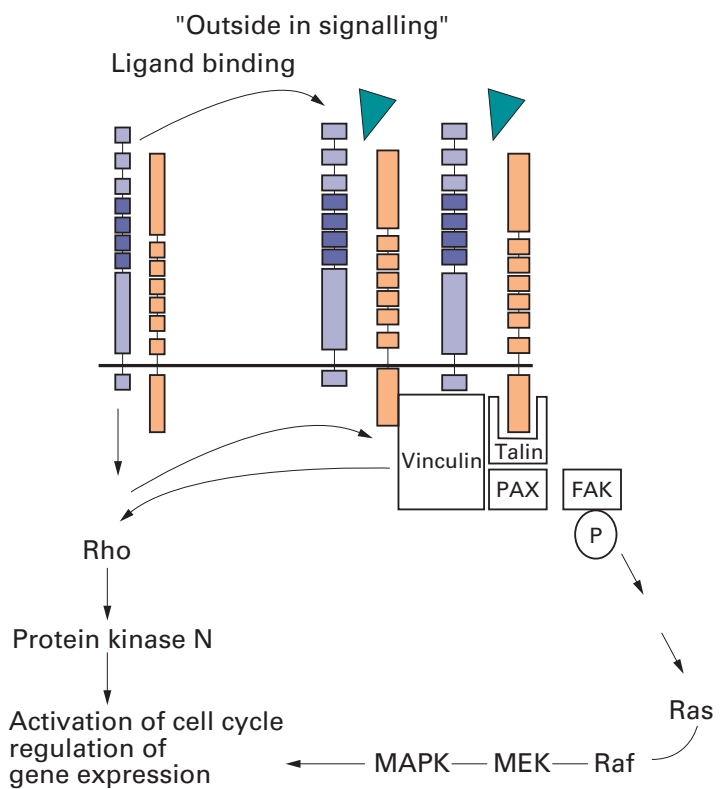

Figure 2 Integrin signalling mechanisms: "inside out" signalling is mediated by intracellular events and may occur by Rho dependent reorganisation of the cytoskeleton, or by changes in phosphorylation of integrin cytoplasmic domains or integrin associated proteins. "Outside in" signalling is generated by integrin-ligand binding and clustering, mediated by Rho A, organisation of the focal adhesion complex, activation of FAK with subsequent activation of MAP kinases, which then regulate gene expression. FAK, focal adhesion kinase; MAP, mitogen activated protein; MEK, MAP kinase kinase; $P$, phosphorylation; PAX, paxillin.

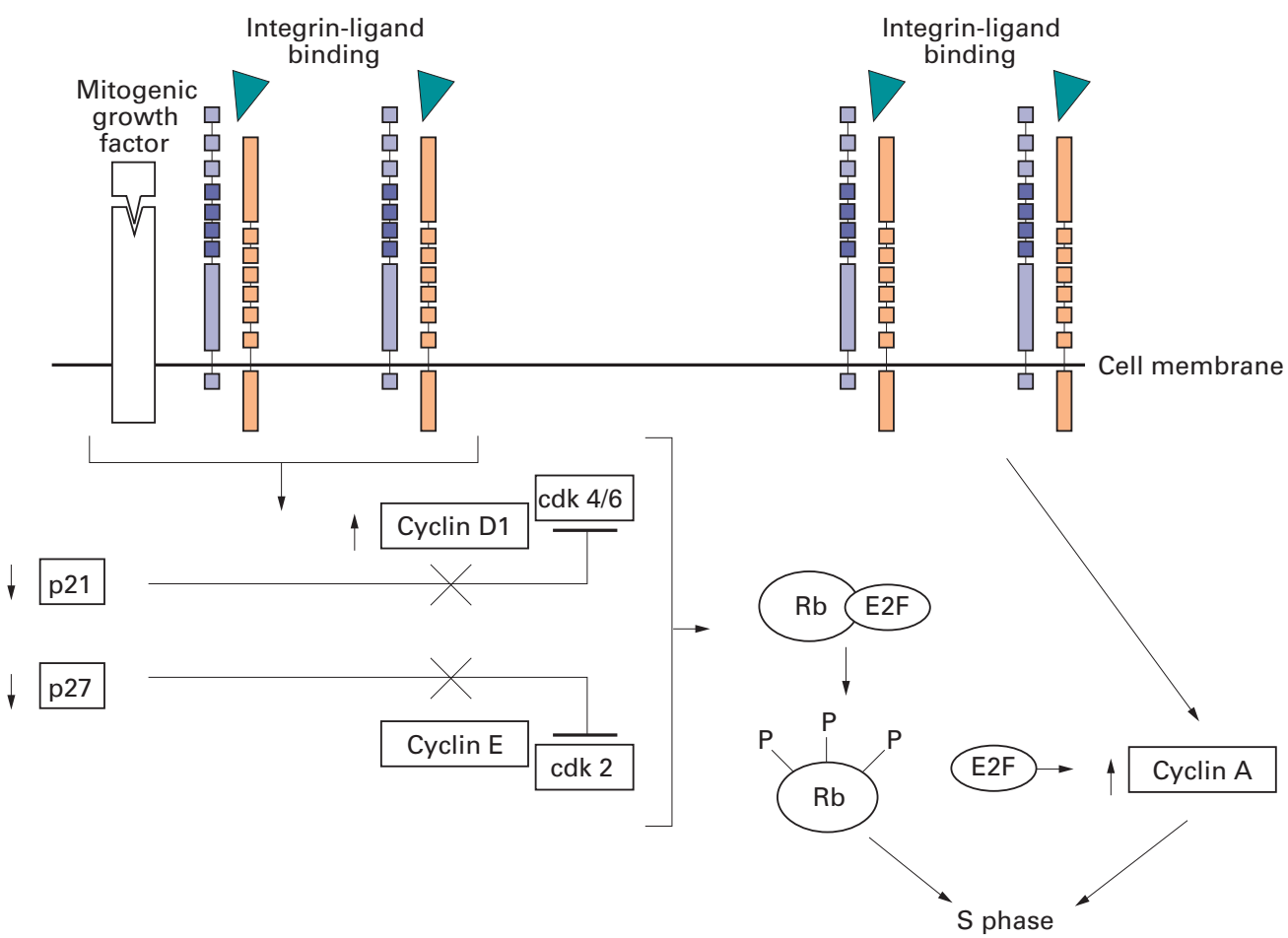

Figure 3 Influence of integrin mediated signalling on cell cycle progression. Both integrin-ligand binding and growth factors are required to induce cyclin D1 and repress the cyclin dependent kinase (cdk) inhibitory proteins p21 and p27. Active cyclin D1-cdk4/6 and cyclin E-cdk2 phosphorylate the Rb protein, releasing E2F, which induces expression of cyclin A. Integrin-ligand binding is also required for growth factor independent cyclin A induction. Cyclin A activity is required for progression into the $S$ phase of the cycle. Rb, retinoblastoma protein; $P$, phosphorylation. 
adaptor protein Shc and activate the Ras-ERK (extracellular signal related protein) signalling pathway, such as $\alpha 1 \beta 1, \alpha 5 \beta 1$, and $\alpha v \beta 3$, may protect cells from undergoing apoptosis, whereas integrins that are not linked to Shc appear to induce apoptosis. ${ }^{27}$ Integrin mediated activation of FAK and subsequent activation of MAP kinases has been implicated in some cell systems as a mechanism of control of apoptosis. Expression of an activated form of FAK in MDCK (Madin-Darby canine kidney) epithelial cells blocks anoikis, ${ }^{28}$ and microinjection of peptides leading to inactivation of FAK, or inhibition of FAK by antisense oligonucleotides, triggers apoptosis in fibroblasts ${ }^{29}$ and rhabdomyosarcoma tumour cells, ${ }^{30}$ respectively. The precise pathways are not yet established, but FAK may act via phosphatidylinositol 3-kinase (PI-3K) to activate the anti-apoptotic protein $\mathrm{Bcl}-2 .{ }^{31}{ }^{32}$

In contrast to these anti-apoptotic signals via integrins, the $\alpha 6 \beta 4$ integrin has been shown to induce apoptosis in a rectal cancer cell line with concomitant upregulation of the cdk inhibitor $\mathrm{p} 21 .^{33}$

DIFFERENTIATION

It is well established that cell-matrix interactions play a crucial role in the development of the differentiated phenotype. In the mouse mammary gland, $\beta 1$ integrin mediated interactions with the extracellular matrix induce synthesis of the milk protein $\beta$-casein. ${ }^{34}$ In human mammary epithelial cell lines, $\alpha 2 \beta 1$ integrin modulates epithelial differentiation and glandular morphogenesis, ${ }^{35}$ and gland formation by colorectal epithelial cells is also $\beta 1$ integrin dependent. ${ }^{36}$ Analysis of knockout mice has indicated a key role for $\alpha 6 \beta 4$ integrin in establishing epithelial cell polarity in basal keratinocytes. ${ }^{37}$ Together, these studies indicate that the characteristics of a cell are largely defined by its expression profile of integrin receptors.

\section{Integrins and cancer}

Many of the processes in which integrins appear to play a central role-anchorage dependent growth, apoptosis, differentiation, and migration-are precisely those that are characteristically dysregulated in malignancy. Therefore, it is not surprising that much attention has focused on the potential involvement of altered integrin expression in cancer.

Many malignancies exhibit altered expression of integrin receptors in comparison with their normal counterparts. ${ }^{38-43}$ The most clear cut association between an altered integrin profile and tumour progression has been demonstrated for malignant melanoma. The collagen receptor $\alpha 2 \beta 1$ is more strongly expressed in invasive melanoma compared with in situ melanoma, ${ }^{44}$ and this reflects in vitro studies, where $\alpha 2 \beta 1$ expression is associated with enhanced invasion of melanoma cell lines, ${ }^{45} 46$ and there is consistent, strong correlation between acquisition of $\alpha v \beta 3$ integrin and both the vertical growth phase of melanoma and metastasis. $^{47}$
Integrin receptor expression can alter tumour cell growth rate. Transfection of Chinese hampster ovary cells with $\alpha 5 \beta 1$ inhibits anchorage independent growth, reduces proliferation, and leads to a non-tumorigenic phenotype when injected into nude mice. ${ }^{48}$ In addition, expression of $\alpha 5 \beta 1$ in HT29 colon cancer cells significantly inhibits proliferation. ${ }^{49}$ By contrast, some integrins appear to regulate proliferation positively. Melanoma cells selected for lack of the $\alpha v \beta 3$ integrin have significantly reduced proliferation and tumorigenicity, which is reversed by re-expression of the integrin..$^{50}$

Resistance to apoptosis is a feature of many malignant cells and such resistance may be the result of aberrant integrin signalling-for example, in rhabdomyosarcoma, downregulation of integrin associated FAK induces apoptosis in these cells, ${ }^{30}$ whereas MDCK cells that overexpress FAK are rescued from apoptosis and become anchorage independent and tumorigenic. ${ }^{28}$

It has been suggested that altered cell-matrix interactions could play a role in the initiation of malignancy by dysregulating pathways that control genomic stability. ${ }^{51}$ Recent studies indicate that cell-matrix interactions can control p53 activity and that in the absence of matrix attachment p53 concentrations are reduced..$^{52}$ When fibroblasts are exposed to $\gamma$ irradiation they exhibit p53 mediated cell cycle arrest. If the cells are released from the substratum they do not show raised p53 concentrations or cell cycle arrest. ${ }^{53}$ This implies that loss of integrin mediated adhesion may predispose cells to the generation of mutations and potentially neoplastic transformation.

Integrins also contribute to cellular migration and metastasis - for example, transfection of melanoma cells with $\beta 3$ integrin promotes cell migration and metastasis, ${ }^{54}$ and migration and invasion of glioma cells is specifically inhibited by antibodies to $\alpha 3 \beta 1$ integrin..$^{55}$ Our laboratory has shown that upregulation of $\alpha 6 \beta 4$ integrin in a breast cancer cell line and redistribution of this integrin to discrete adhesive structures is associated with a significant reduction in invasive behaviour. ${ }^{56}$ One way in which integrins may control the invasive phenotype is through crosstalk with other cell adhesion molecules. The integrin linked kinase (ILK) binds to the cytoplasmic domains of $\beta 1$ and $\beta 3$ integrins, and is activated by integrinligand interactions. ${ }^{57}$ Overproduction of a constitutively active ILK in both intestinal and mammary epithelial cells leads to downregulation of the invasive suppressor protein E-cadherin, and acquisition of an invasive phenotype. $^{58}$

Another important aspect of invasion is proteolytic remodelling of the stroma by enzymes such as the matrix metalloproteinases (MMPs). In rabbit synovial fibroblasts, $\alpha 4 \beta 1$ and $\alpha 5 \beta 1$ integrins differentially regulate the production of MMPs. ${ }^{59} 60$ Tumour cells frequently display an altered integrin repertoire compared with their normal counterparts, and this may be a mechanism whereby cells can 


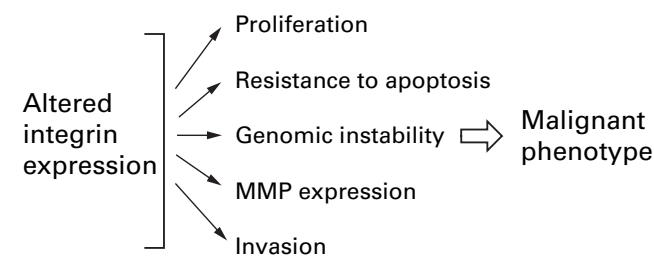

Figure 4 Summary of the processes modulated by integrin signalling that might influence the development of the malignant phenotype. MMP, matrix metalloproteinase.

control the synthesis and secretion of proteolytic enzymes. In human melanoma cell lines, the differential expression of $\alpha 5 \beta 1$ integrin and $\alpha v \beta 3$ integrin modulates release of $\mathrm{MMP}-2$ and subsequent invasive behaviour, ${ }^{61}$ and in colon cancer cells, $\alpha v \beta 6$ integrin mediated signalling controls release of the gelatinase enzyme MMP-9. ${ }^{62}$ A physical relation between integrin receptors and proteolytic enzyme systems has also been described between the $\alpha v \beta 3$ integrin and $\mathrm{MMP}-2{ }^{63}$ which appears to provide migratory cells with coordinated matrix degradation and motility.

\section{Summary}

The integrin family of receptors forms a diverse group of molecules, which through their interactions with different matrix molecules and with different cytoskeletal elements can generate a wide range of cellular responses. It is now evident that integrin mediated signalling can influence proliferation, apoptosis, differentiation, and migration, and their involvement in such fundamental processes suggests that altered function or expression of integrins by a cell may influence the development of the malignant phenotype (fig 4).

Dr JL Jones acknowledges the support of the Royal College of Pathologists BUPA Research Fellowship.

Hynes RO. Integrins: versatility, modulation and signaling in cell adhesion. Cell 1992;69:11-25.

2 Takada YE, Murphy P, Pil C, et al. Molecular cloning and expression of the CDNA for alpha 3 subunit of human alpha 3 beta 1 (VLA-3), an integrin receptor for fibronectin, laminin and collagen. $\mathcal{F}$ Cell Biol 1991;115: 257-66.

3 Guan JL, Hynes RO. Lymphoid cells recognise an alternatively spliced segment of fibronectin via the integrin receptor alpha 4 beta 1 . Cell 1990;60:53-61

4 Elices MJ, Urry LA, Hemler MA. Receptor function for the integrin VLA-3: fibronectin, collagen and laminin binding are differentially influenced by ARG-GLY-ASP peptide and by divalent cations. F Cell Biol 1991;112:169-87.

5 Yamada KM, Miyamoto S. Integrin transmembrane signalling and cytoskeletal control. Curr Opin Cell Biol 1995;7: ling and

6 Borradori L, Sonnenberg A. Hemidesmosomes: roles in adhesion, signalling and human diseases. Curr Opin Cell adhesion, signalling

7 Nievers MG, Schaapveld RQJ, Oomen LCJM, et al. Ligandindependent role of the $\beta 4$ integrin subunit in the 72 .

8 Schwartz MA, Schaller MD, Ginsberg MH. Integrins: emerging paradigms of signal transduction. Annual Review of Cell Biology and Developmental Biology 1995;11:549-600.

Juliano RL, Haskill S. Signal transduction from the extracellular matrix. F Cell Biol 1993;120:577-85.

10 O'Toole TE, Katagiri Y, Faull RJ, et al. Integrin cytoplasmic domains mediate inside-out signal transduction. $f$ Cell Bio 1994;124:1047-59.

11 Coppolino M, Leung-Hagesteijn C, Dedhar S, et al. Inducible interaction of integrin $\mathrm{a} 2 \mathrm{~b} 1$ with calreticulin: dependence on the activation state of the integrin. $7 \mathrm{Biol}$ Chem 1996;270:23132-8.

12 Dedhar S, Hannigan GE. Integrin cytoplasmic interactions and bidirectional transmembrane signalling. Curr Opin Cell Biol 1996;8:657-69.

13 Nobes CD, Hall A. Rho, Rac and Cdc42 GTPases regulate the assembly of multimolecular focal complexes associated
with actin stress fibers, lamellipodia and filopodia. Cell with actin stress
14 Burbelo PD, Miyamoto S, Utani A, et al. p190-B, a new member of the Rho GAP family, and Rho are induced to member of the Rho GAP family, and Rho are induced to cluster after

15 Zhu X, Assoian RK. Integrin-dependent activation of MAP kinase: a link to shape-dependent cell proliferation. Mol Biol Cell 1995;6:273-82.

16 Chen Q, Kinch MS, Lin TH, et al. Integrin mediated cell adhesion activates mitogen-activated protein kinases. $\mathcal{F}$ Biol Chem 1994;269:26602-5.

17 Dike LE, Farmer SR. Cell adhesion induces expression of growth associated genes in suspension arrested fibroblasts. Proc Natl Acad Sci USA 1988;85:6792-6.

18 Assoian RK. Anchorage-dependent cell cycle progression. $\mathcal{f}$ Cell Biol 1997;136:1-4.

19 Weinberg RA. The retinoblastoma protein and cell cycle control. Cell 1995;81:323-30.

20 Sherr CJ. G1 phase progression: cycling on cue. Cell 1994;79:551-5

21 Shulze A, Zerfass K, Spitkovsky D, et al. Cell cycle regulation of the cyclin A gene promotor is mediated by a variant E2F site. Proc Natl Acad Sci USA 1995;92:112648.

22 Sherr CJ, Roberts JR. Inhibitors of mammalian cyclindependent kinases. Genes Dev 1995;9:1149-63.

23 Bohmer RM, Scharf E, Assoian RK. Cytoskeletal integrity is required throughout the mitogen stimulation phase of the cell cycle and mediates the anchorage-dependent expression of cyclin D1. Mol Biol Cell 1996;7:101-11.

24 Zhu X, Ohtsubo M, Bohmer RM, et al. Adhesiondependent cell cycle progression linked to the expression of cyclin D1, activation of cyclin E-cdk2, and phosphorylation of the retinoblastoma protein. I Cell Biol 1996;133: 391-403.

25 Iwig M, Czeslick E, Muller A, et al. Growth regulation by cell shape alteration and organisation of the cytoskeleton. Eur f Cell Biol 1995;67:145-57.

26 Frisch SM, Francis H. Disruption of epithelial cell-matrix interactions induces apoptosis. F Cell Biol 1994;124:61926.

27 Wary K, Mainiero F, Isakoff S, et al. The adaptor protein Shc couples a class of integrins to the control of cell cycle progression. Cell 1996;87:733-43.

28 Frisch S, Vuori K, Ruoslahti E, et al. Control of adhesion-dependent cell survival by the focal adhesion adhesion-dependent cell survival

29 Hungerford JE, Compton MT, Matter ML, et al. Inhibition of ppFAK ${ }^{125}$ in cultured fibroblasts results in apoptosis. $\mathcal{F}$ Cell Biol 1996;135:1383-90.

$30 \mathrm{Xu} \mathrm{L-H}$, Owens LV, Sturge GC, et al. Attenuation of the expression of the focal adhesion kinase induces apoptosis in tumour cells. Cell Growth Differ 1996;7:413-18.

31 Chen HC, Guan J-L. Association of focal adhesion kinase with its potential substrate phosphatidylinosit

32 Datta SR, Dudek H, Tao X, et al. Akt phosphorylation of BAD couples survival signals to the cell-intrinsic death machinery. Cell 1997;91:231-41.

33 Clarke A, Lotz M, Chao C, Mercurio A. Activation of the p21 pathway of growth arrest and apoptosis by the $\beta 4$ integrin cytoplasmic domain. I Biol Chem 1995;270: 22673-6.

34 Streuli CH, Schmidhauser C, Bailey $\mathrm{N}$, et al. Laminin mediates tissue-specific gene expression in mammary epithelia. F Cell Biol 1995;129:591-603.

35 Zutter MM, Santoro SA, Staatz WD, et al. Re-expression of the $\alpha 2 \beta 1$ integrin abrogates the malignant phenotype of breast carcinoma cells. Proc Natl Acad Sci USA 1995;92: 7411-15.

36 Pignatelli $M$, Bodmer WF. Integrin-receptor-mediated differentiation and growth inhibition are enhanced by transforming growth factor-beta in colorectal tumour cells grown in collagen gel. Int $\mathcal{F}$ Cancer 1989;44:518-23.

37 Dowling J, Yu QC, Fuchs E. Beta4 integrin is required for hemidesmosome formation, cell adhesion and cell survival. 7 Cell Biol 1996;134:559-72.

38 Pignatelli M, Smith MEF, Bodmer WF. Low expression of collagen receptors in moderate and poorly differentiated colorectal adenocarcinomas. Br f Cancer 1991;61:636-8.

39 Koretz K, Schlag P, Boumsell L, et al. Expression of VLA-alpha 2, VLA-alpha 6, and VLA-beta 1 chains in normal mucosa and adenomas of the colon, and in colon carcinomas and their liver metastases. Am f Pathol 1991;138: 741-50.

40 Hall PA, Coates P, Lemoine NR, et al. Characterization of integrin chains in normal and neoplastic human pancreas. 7 Pathol 1991;165:33-41.

41 Damjanovich L, Albelda SM, Mette SA, et al. Distribution of integrin cell adhesion receptors in normal and malignant lung tissue. Am F Respir Cell Mol Biol 1992;6:197-206.

42 Jones JL, Critchley DR, Walker RA. Alteration of stromal protein and integrin expression in breast - a marker of premalignant change? F Pathol 1992;167:399-406.

43 Pignatelli $M$, Cardillo MR, Hanby A, et al. Integrins and their accessory adhesion molecules in mammary carcinomas: loss of polarization in poorly differentiated tumors. Hum Pathol 1992;23:1159-66.

44 van Duinen CM, van den Broek LJ, Vermeer BJ, et al. The distribution of cellular adhesion molecules in pigmented skin lesions. Cancer 1994;73:2131-9.

45 Klein CE, Steinmayer T, Kaufmann D, et al. Identification of a melanoma progression antigen as integrin VLA-2. $\mathcal{F}$ Invest Dermatol 1991;96:281-4. 
46 Klein CE, Dressel D, Steinmayer T, et al. Integrin alpha 2 beta 1 is upregulated in fibroblasts and highly aggressive melanoma cells in three-dimension mediates the reorga

47 Nesbit M, Herlyn M. Adhesion receptors in human melanoma progression. Invasion Metastasis 1994;14:13146.

48 Giancotti FG, Ruoslahti E. Elevated levels of the alpha 5 beta 1 fibronectin receptor suppress the transformed phenotype of Chinese hamster ovary cells. Cell 1990;60: 849-59.

49 Varner JA, Emerson DA, Juliano RL. Integrin $\alpha 5 \beta 3$ expression negatively regulates cell growth: reversal by attachment to fibronectin. Mol Biol Cell 1995;6:725-40.

50 Felding Habermann B, Mueller BM, Romerdahl CA, et al. Involvement of integrin alpha V gene expression in human
melanoma tumorigenicity. $\mathcal{F}$ Clin Invest 1992;89:2018-22.

51 Tlsty TD. Cell-adhesion-dependent influences on genomic instability and carcinogenesis. Curr Opin Cell Biol 1998;10: instability

52 Nigro JM, Aldape KD, Hess SM, et al. Cellular adhesion regulates p 53 protein levels in primary human keratinocytes. Cancer

53 Gadbois DM, Bradbury EM, Lehnert BE. Control of radiation-induced G1arrest by cell-substratum interactions. Cancer Res 1997;57:1151-6.

54 Filardo EJ, Brooks PC, Deming SL, et al. Requirement of the NPXY motif in the integrin $\beta 3$ cytoplasmic tail for melanoma cell migration in vitro and in vivo. 7 Cell Biol 1995;130:441-50.

55 Fukushima Y, Ohnishi T, Arita N, et al. Integrin $\alpha 3 \beta 1$-mediated interaction with laminin 5 stimulates adhesion, migration and invasion of malignant glioma cells. Int f Cancer 1998;76:63-72.
56 Jones JL, Royall JE, Critchley DR, et al. Modulation of myoepithelial associated $\alpha 6 \beta 4$ integrin in a breast cancer cell line alters invasive potential. Exp Cell Res1997;235: 325-33.

57 Hannigan GE, Leung-Hagesteijn C, Fitz-Gibbon L, et al. Regulation of cell adhesion and anchorage-dependent growth by a new $\beta 1$-integrin-linked protein kinase. Nature 1996;379:91-6.

58 Novak A, Hsu S-C, Leung-Hagestijn C, et al. Cell adhesion and the integrin linked kinase regulate the LEF-1 and B-catenin signalling pathways. Proc Natl Acad Sci USA 1998;95:4374-9.

59 Werb Z, Tremble PM, Behrendtsen O, et al. Signal transduction through the fibronectin receptor induces collagenase and stromelysin gene expression. F Cell Biol 1989; 109:877-89.

60 Huhtala P, Humphries MJ, McCarthy JB, et al. Cooperative signaling by alpha 5 beta 1 and alpha 4 beta 1 integrins regulates metalloproteinase gene expression in fibroblasts adhering to fibronectin. $\mathcal{F}$ Cell Biol 1995;129:867-79.

61 Seftor RE, Seftor EA, Stetler Stevenson WG, et al. The 72 $\mathrm{kDa}$ type IV collagenase is modulated via differential expression of alpha $\mathrm{v}$ beta 3 and alpha 5 beta 1 integrins during human melanoma cell invasion. Cancer Res1993;53: 3411-15.

62 Niu J, Gu X, Turton J, et al. Integrin-mediated signalling of gelatinase B secretion in colon cancer cells. Biochem Biophys Res Commun 1998;249:287-91.

63 Brooks P, Stromblad S, Sanders L, et al. Localisation of matrix metalloproteinase MMP-2 to the surface of invasive cells by interaction with integrin avß3. Cell 1996;85:68393. 